\title{
Supressão de Plantas daninhas por leguminosas Anuais em Sistema Agroecológico na Pré-Amazônia ${ }^{1}$
}

\author{
Suppression of Weeds by Annual Leguminous Plants Under Amazon Agroecological System
}

\begin{abstract}
ARAUJO, J.C. ${ }^{2}$, MOURA, E.G. ${ }^{3}$, AGUIAR, A.C.F. ${ }^{3}$ e MENDONÇA, V.C.M. ${ }^{2}$
RESUMO - Este trabalho teve por objetivos identificar e avaliar a agressividade potencial das plantas daninhas em um agrossistema com leguminosas herbáceas anuais como cobertura de solo. Foram plantadas, nas ruas de um sistema de aléias de sombreiro (Clitoria fairchildiana) e no final do período agrícola, as leguminosas mucuna-preta, feijão-guandu, feijão-de-porco e calopogônio, em sistema de blocos ao acaso com cinco repetições. Para estudo da dinâmica da composição florística, avaliaram-se a freqüência, densidade, dominância, similaridade, diversidade de espécies e biomassa das plantas daninhas. Foram identificadas 42 espécies de plantas espontâneas, das quais as mais freqüentes e de maior densidade e dominância foram Leptochoa virgata, Panicum laxume Sidasp. Não foram detectadas diferenças significativas para densidade, número de espécies, diversidade e biomassa entre as plantas daninhas emergidas nos quatro tratamentos com leguminosas; nem destas em relação ao controle.
\end{abstract}

Palavras-chave: sistema em aléias, cultura de cobertura, dinâmica populacional.

\begin{abstract}
This study evaluated the efficiency of cover legumes in suppressing weed. A field experiment was arranged in a randomized block design with five replications in an alley cropping system, using Clitoria fairchildiana and four cover species, Mucuna aterrima, Cajanus cajan, Canavalia ensiformes and Calopogonium mucunoides. Weed frequency, density, diversity and biomass were evaluated with 42 weed species being identified. The most frequent and presenting the highest density and dominance were Leptochoa virgata, Panicumlaxum and Sida sp. No significant differences were detected in density, number of species, diversity and biomass among the four legumes, nor between them and the control.
\end{abstract}

Keywords: alley cropping, cover crop, population dynamics.

\section{INTRODUÇÃO}

A premissa fundamental das culturas de cobertura, como um componente do manejo integrado de plantas daninhas, é a de que elas possam exercer efeito diferencial sobre plantas daninhas e a cultura, resultando em diminuição relativa do vigor das primeiras (Williams et al., 1998). Embora os efeitos da cobertura sobre populações de plantas possam advir de processos alelopáticos, a formação de barreira física, por meio da biomassa acumulada, diminuindo a incidência de luz sobre a superficie, onde estariam os bancos de sementes, foi considerada a principal vantagem da presença da cobertura por Bond \& Grundy (2001) e Hatcher $\&$ Melander (2003).

O uso de culturas de cobertura para produção de adubo verde e redução das populações

Recebido para publicação em 29.6.2006 e na forma revisada em 15.5.2007.

Alunos do Programa de Pós-Graduação em Agroecologia, Curso de Mestrado da Universidade Estadual do Maranhão; ${ }^{3}$ Professores do Programa de Pós-Graduação em Agroecologia, Universidade Estadual do Maranhão. Caixa Postal 3004, 65054-970, São Luís, Maranhão<egmoura@elo.com.br>. 
das plantas tem sido avaliado e recomendado por alguns autores, porém é necessária a escolha da espécie adequada, principalmente quanto à uniformidade de crescimento (Severino \& Christoffoleti, 2004). A mucuna-preta, usada como cultura de cobertura, é capaz de suprimir até $100 \%$ das plantas daninhas a partir da oitava semana de emergência, cobrindo totalmente a área até a fase de maturação de seus frutos, ao passo que o feijão-de-porco é capaz de cobrir $83 \%$ da superficie do solo, com a mesma densidade de plantio da mucuna-preta (seis plantas por metro linear). O feijão-guandu, por sua vez, apresenta baixa capacidade de cobertura de solo e, por isso, sua capacidade de supressão de plantas daninhas nos seus primeiros estádios de crescimento também é reduzida (Favero et al., 2001).

Bond \& Grundy (2001) comentam que coberturas de solo, vivas ou não, são mais eficientes na prevenção de germinação de sementes de plantas daninhas e emergência de plântulas que na supressão de plantas já estabelecidas. O uso de culturas de cobertura para controle de plantas daninhas deve ser visto como um componente do manejo integrado que, combinado com outros métodos de controle biológico (cultural, mecânico e químico), pode contribuir para a redução das taxas de aplicação de herbicidas em pós-emergência e para o preparo da área para plantio direto, visto que o uso de herbicidas para dessecar a cultura de cobertura é prática rotineira nesse sistema de cultivo (Williams et al., 1998).

Nas condições de alta precipitação e fragilidade dos solos do trópico úmido, o uso do plantio direto em solo coberto é a principal prática recomendada para garantir a sustentabilidade dos agrossistemas (Moura, 2004); contudo, a diversidade e a agressividade elevada das plantas daninhas, aliadas à continuação do período chuvoso após a época da colheita da safra principal, dificultam o manejo das culturas sem o uso de herbicidas, uma vez que o crescimento de plantas daninhas cujas sementes emergem no início das chuvas é favorecido. Em sistemas agroecológicos, dada sua maior complexidade e as exigências quanto à qualidade ambiental do agroecossistema, o manejo das culturas exige conhecimento melhor da distribuição, da diversidade e ecologia das plantas daninhas e da possibilidade de combinar a supressão das plantas com a reciclagem de nutrientes, a fim de melhorar a produtividade das lavouras, com menor entrada de herbicidas e a qualidade ambiental do agrossistema (Poudel et al., 2002). O sistema de cultivo em aléias - por possibilitar essas condições - pode ser capaz de prover a segurança alimentar de milhões de pessoas que vivem nos trópicos, com menores aplicações de insumos internos que a agricultura convencional. Esse sistema de cultivo combina em uma mesma área espécies arbóreas, preferencialmente leguminosas, e culturas anuais, visando reunir em um mesmo espaço e ao mesmo tempo os processos de regeneração da fertilidade do solo e intensificação da ciclagem de nutrientes, as quais são separadas temporariamente na agricultura de derrubadaqueima-pousio (Atta-Krah et al., 1989; Kang et al., 1990). O uso de Clitoria fairchildiana em aléias foi recomendado por Ferraz Júnior (2000), por sua capacidade de produção de biomassa em condições de deficiência de água no solo.

Os objetivos deste trabalho foram identificar e avaliar a agressividade potencial das plantas daninhas em um agroecossistema e o efeito da introdução de leguminosas anuais sobre a supressão dessas plantas, para ampliação do conhecimento sobre o manejo agroecológico de sistemas adequados às realidades ambientais e socioeconômicas da região PréAmazônica maranhense.

\section{MATERIAL E MÉTODOS}

O experimento foi realizado em uma área de assentamento do INCRA, no municipio de Miranda do Norte-MA, localizado a $3^{\circ} 36^{\prime}$ de latitude sul e $45^{\circ} 24^{\prime}$ de longitude oeste, onde foi implantado no início de 2002, em um terreno plano (1,0 ha), um sistema de cultivo em aléias com Clitoria fairchildiana, uma leguminosa arbórea nativa localmente denominada sombreiro. A temperatura média anual da região é de $27{ }^{\circ} \mathrm{C}$ e a pluviosidade média anual, de $1.615 \mathrm{~mm}$, com o período chuvoso ocorrendo de dezembro a maio. O solo foi classificado como Plintossolo Argilúvico distrófico, de textura franca siltosa, com as seguintes características químicas na camada de $0-20 \mathrm{~cm}$ de profundidade: $\mathrm{pH}\left(\mathrm{H}_{2} \mathrm{O}\right)=5,9 ; \mathrm{P}\left(\mathrm{mg} \mathrm{dm}^{-3}\right)=10 ; \mathrm{K}$ $\left(\mathrm{mmol}_{\mathrm{c}} \mathrm{dm}^{-3}\right)=4,1 ; \mathrm{Ca}\left(\mathrm{mmol}_{\mathrm{c}} \mathrm{dm}^{-3}\right)=31 ; \mathrm{Mg}$ 
$\left(\mathrm{mmol}_{\mathrm{c}} \mathrm{dm}^{-3}\right)=17 ; \mathrm{H}+\mathrm{Al}\left(\mathrm{mmol}_{\mathrm{c}} \mathrm{dm}^{-3}\right)=10 ; \mathrm{e}$ $\mathrm{V}(\%)=84,4$.

O sombreiro foi semeado em espaçamento de $2,0 \times 0,5 \mathrm{~m}$. As leguminosas herbáceas foram semeadas manualmente nas entrelinhas das aléias de sombreiro em espaçamento de $0,50 \times 0,50 \mathrm{~m}$, após a colheita do arroz, cultivado como planta principal. O delineamento experimental foi em blocos casualizados, com cinco repetições e cinco tratamentos. As parcelas eram constituídas de duas faixas da cultura principal com uma fileira de Clitoria fairchildiana no centro, com o tamanho de $10 \mathrm{x}$ $4 \mathrm{~m}$ (Figura 1). Os tratamentos foram os seguintes: T1 - mucuna-preta (Mucuna aterrima); T2 feijão-guandu (Cajanus cajan) variedade taipeiro; T3 - feijão-de-porco (Canavalia ensiformes); T4 - calopogônio (Calopogonium mucunoides); e T5 - tratamento controle, sem leguminosa de cobertura. As leguminosas foram semeadas com densidade de 80.000 plantas por hectare (duas plantas por cova). Aos 202 dias após a semeadura das leguminosas - período que coincidiu com o final da estação seca na região - iniciou-se a coleta, contagem e identificação das plantas daninhas nas parcelas experimentais. Nesse período, o feijão-de-porco estava com vagens maduras, o feijão-guandu ainda não havia atingido o estádio de florescimento e a mucuna-preta e o calopogônio haviam completado a fase reprodutiva, a qual foi antecipada com o aumento do déficit hídrico, no final do periodo seco, o que não impediu que essas espécies exercessem influência sobre a supressão de plantas daninhas quando de sua fase vegetativa.

$\mathrm{Na}$ coleta das plantas daninhas utilizouse um quadrado de $0,5 \mathrm{~m}$ de lado (Ikuenobe $\&$ Anoliefo, 2003), lançado ao acaso em quatro pontos dentro da parcela experimental (Hyvönen et al., 2003; Jakelaitis et al., 2003). A identificação das plantas foi realizada de acordo com Kissmann \& Groth $(1992,1995)$ e Kissmann (1997). Após a identificação, as plantas foram contadas e secas em estufa a $70{ }^{\circ} \mathrm{C}$, até massa constante (Marenco, 1999). Para estudo da dinâmica populacional das plantas daninhas nos vários tratamentos, foi realizada uma comparação da composição florística e dos índices que expressam a estrutura horizontal da vegetação, ou seja, freqüência (Jakelaits et al., 2003), densidade, dominância

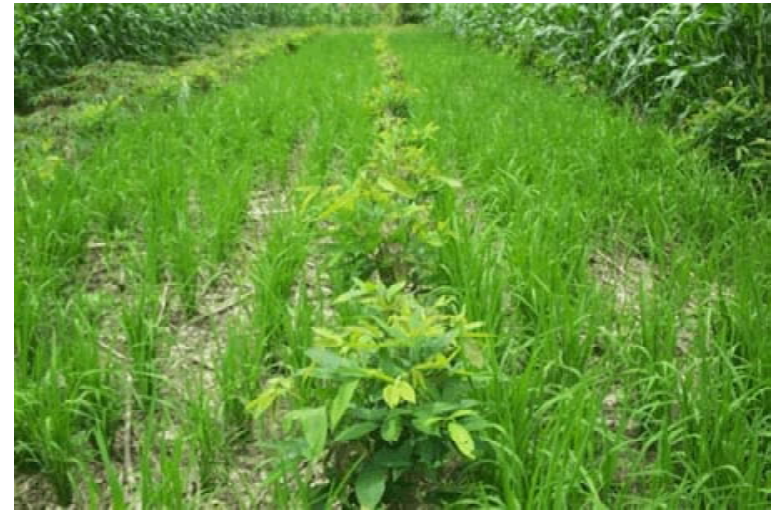

Figura 1 - Exemplo de parcela com a cultura principal e três fileiras de aléias com sombreiro em fase de brotação.

e diversidade de espécies. A dominância foi representada pela média entre freqüencia e densidade relativas.

A avaliação da similaridade florística entre os tratamentos foi realizada para dados qualitativos (presença e ausência de espécies), a partir do indice de similaridade de Sorensen (Pinto-Coelho, 2000), que é dado por: $S=2 C / A$ $+B(0 \leq \mathrm{S} \leq 1$ ou $0 \leq \mathrm{S} \leq 100)$, em que $S$ é o índice de similaridade; $A$, o número de espécies presentes no tratamento $A ; B$, o número de espécies presentes no tratamento $\mathrm{B}$; e $C$, o número de espécies comuns nos tratamentos A e B. A diversidade da composição florística foi obtida a partir do índice de Shannon-Wiener (Pinto-Coelho, 2000), que é dado por: $\mathrm{H}=-\sum_{\mathrm{i}=1}^{\mathrm{s}}$ $\mathrm{p}_{\mathrm{i}}$ ln pi, em que s é o número de espécies; pi, a razão da densidade do número de indivíduos da espécie i pela densidade total de todas as espécies; e ln, o logaritmo natural de pi. Os dados de número de espécies, diversidade espécies, densidade de plantas e biomassa foram submetidos à analise de variância, sendo as médias comparadas pelo teste de Tukey $(P \leq 0,05)$. Realizou-se, também, análise de regressão entre as produções de biomassa das plantas daninhas em função da presença das leguminosas.

\section{RESULTADOS E DISCUSSÃO}

Confirmando a expectativa da grande diversidade de espécies de plantas daninhas nos agrossistemas do trópico úmido, foram identificadas neste experimento 14 espécies de monocotiledôneas, distribuídas em quatro famílias, 
e 28 espécies de dicotiledôneas, distribuídas em 15 famílias (Tabela 1). As famílias Gramineae, Malvaceae e Cyperaceae - com oito, seis e quatro espécies, respectivamente - apresentaram os maiores números de espécies. Das espécies de plantas daninhas monocotiledôneas, três são anuais e 11 perenes; entre as dicotiledôneas, 15 são anuais e 13 perenes (Tabela 1).

Das 42 espécies de plantas daninhas de ocorrência na área do experimento e listadas na Tabela 2 , apenas $26 \%$ delas tiveram freqüência detectada no tratamento feijão-deporco; 40,5\% foram detectadas nas parcelas com guandu, calopogônio e controle; e 38\%, nas parcelas com mucuna-preta. As espécies Leptochloa virgata, Panicum laxum e Sida sp. ocorreram em todos os tratamentos - as duas primeiras sempre com densidades acima de 7 plantas $\mathrm{m}^{-2}$, o que as torna mais importantes a serem consideradas em um programa de controle alternativo nos agrossistemas regionais. A espécie $L$. virgata foi a mais freqüente e apresentou sempre densidade maior que 20 plantas $\mathrm{m}^{2}$, com exceção do tratamento com feijão-de-porco, em que a densidade foi de $16 \mathrm{~g} \mathrm{~m}^{-2}$ (Tabela 2). O rápido crescimento, a boa cobertura do solo e a resistência à seca da leguminosa foram os principais fatores responsáveis por esse resultado. Os dados de densidade também indicaram que o feijão-guandu e o calopogônio não afetaram o crescimento da espécie $L$. virgata. A espécie $P$. laxum, com segunda maior densidade (de 7 a 24 plantas $\mathrm{m}^{2}$ ), teve o crescimento mais afetado pelo feijãoguandu, cujo porte mais elevado pode ter influenciado o desenvolvimento desta planta daninha. A terceira planta daninha de maior ocorrência, Sida sp., espécie dicotiledônea de maior importância do sistema, demonstrou um padrão diferenciado, com freqüência e densidade afetadas conjuntamente, principalmente nas parcelas com feijão-guandu e calopogônio. Sida glaziovii, que também ocorreu em todos os tratamentos, com a quarta maior freqüência $(2,3$ a $11,1 \%)$, mostrou densidade menor $(0,2$ a 2,2 plantas $\mathrm{m}^{2}$ ) do que a da espécie Eleusine indica, que não ocorreu nas parcelas com feijão-guandu.

As espécies $L$. virgatae $P$. laxum foram dominantes em todos os tratamentos; a primeira dominou no tratamento com feijão-guandu, com 50,5\% de presença, e a segunda, no tratamento controle, com dominância de 26,6\% (Figura 2).

A menor dominância de L. virgata ocorreu no tratamento controle, com $28,2 \%$, que foi o tratamento em que a espécie mais dominante foi $P$. laxum. Das espécies de plantas daninhas dicotiledôneas, a mais dominante foi Sida sp., particularmente nas parcelas com feijão-deporco, em que a sua dominância foi superior à de $P$. laxum. Ressalte-se que no tratamento com feijão-de-porco foi encontrada a maior população de espécies de plantas daninhas dicotiledôneas, representada, sobretudo, por espécies do gênero Sida spp., indicando possivel processo de sucessão com prejuízo das espécies monocotiledôneas. Isso pode ser visualizado especialmente em relação às espécies $P$. laxum e Eleusine indica, que ocorreram em menor freqüência quando as espécies como Sida sp. e $S$. glaziovï dominavam nos tratamentos com leguminosa de cobertura (Figura 2).

Das 42 espécies de plantas daninhas encontradas na área do experimento, as espécies L. virgata, P. laxum, Sidasp., E.indicae S. glaziovï, representadas na Figura 1, em conjunto, apresentaram sempre dominância superior a $70 \%$ em todos os tratamentos. Em geral, do número total de espécies num componente trófico ou numa comunidade como um todo, uma porcentagem relativamente pequena é abundante ou dominante (Odum, 1988), e essas espécies abundantes tendem a desfavorecer a qualidade do ambiente relativa aos indicadores de biodiversidade (Marshall et al., 2003). O tratamento em que foi utilizado feijãode-porco como cultura de cobertura mostrou a menor densidade de plantas infestantes (44 plantas $\mathrm{m}^{2}$ ), porém não diferiu estatisticamente dos demais tratamentos (Tabela 3).

Segundo Marshall et al. (2003), não é fácil prever a quantidade de plantas daninhas em uma comunidade, dado o caráter generalista de sua ocorrência e das suas variações, que são traços característicos dessas espécies. Além disso, por serem de estratégia $r$, ou seja, de alto potencial reprodutivo (Gliessman, 2001), elas estão bem adaptadas a ambientes com perturbações periódicas, como a seca (Odum, 1988), o que lhes confere rápida capacidade de recuperação aos primeiros sinais de 
Tabela 1 - Espécies de plantas daninhas monocotiledôneas e dicotiledôneas da área experimental

\begin{tabular}{|c|c|c|}
\hline Nome comum & Espécie & Família \\
\hline \multicolumn{3}{|c|}{ Monocotiledôneas } \\
\hline $\begin{array}{l}\text { Tiriricão, tiririca } \\
\text { Tiririca } \\
\text { Tiririca } \\
\text { Junca, tiririca }\end{array}$ & $\begin{array}{l}\text { Cyperus esculentus } \mathrm{L} . \\
\text { Cyperus flavus (Vahl) Nees } \\
\text { Cyperus sp. } \\
\text { Cyperus surinamensis } \text { Rottb }\end{array}$ & Cyperaceae \\
\hline $\begin{array}{l}\text { Grama-missioneira } \\
\text { Capim-pé-de-galinha } \\
\text { Capim-de-burro } \\
\text { Capim-pé-de-galinha } \\
\text { Pé-de-galinha } \\
\text { Capim-de-capivara } \\
\text { Capim-do-brejo } \\
\text { Capim-capela }\end{array}$ & $\begin{array}{l}\text { Axonopus compressus (Sw) Beauv. } \\
\text { Chloris sp. } \\
\text { Cynodon dactylon (L.) Pers. } \\
\text { Eleusine indica (L.) Gaert. } \\
\text { Leptochoa virgata (L.) P.Beauv } \\
\text { Panicum laxum Swartz } \\
\text { Paspalum conspersum } \text { Schrad. } \\
\text { Sporobolus indicus } \text { (L.) R.Br. }\end{array}$ & $\begin{array}{c}\text { Gramineae } \\
\text { (Poaceae) }\end{array}$ \\
\hline Arumarana, caeté & Thalia geniculata $\mathrm{L}$. & Marantaceae \\
\hline Babaçu & Orbignya spp. & Arecaceae \\
\hline \multicolumn{3}{|c|}{ Dicotiledôneas } \\
\hline Caruru, bredo & Amaranthus deflexus L. & Amaranthaceae \\
\hline $\begin{array}{l}\text { Agrião-do-brejo } \\
\text { Aldodão-de-preá }\end{array}$ & $\begin{array}{l}\text { Eclipta alba }(\text { L.) Hassk. } \\
\text { Emilia sonchifolia } \text { (L.) DC. }\end{array}$ & $\begin{array}{c}\text { Asteraceae } \\
(\text { Compositae })\end{array}$ \\
\hline $\begin{array}{l}\text { Trapoeraba } \\
\text { Trapoerabinha }\end{array}$ & $\begin{array}{l}\text { Commelina benghalensis L. } \\
\text { Murdania nudiflora } \text { (L.) Brenan }\end{array}$ & Commelinaceae \\
\hline Gervão-branco & $\begin{array}{l}\text { Chamaesyce prostrata (Ait.) Small } \\
\text { Croton glandulosus L. } \\
\text { Euphorbia comosa Vell. }\end{array}$ & Euphorbiaceae \\
\hline $\begin{array}{l}\text { Bamburral } \\
\text { Hortelã, mentinha }\end{array}$ & $\begin{array}{l}\text { Hyptis suaveolens (L.) Poit. } \\
\text { Leucas martinicensis (Jacq.) W.T.Aiton }\end{array}$ & $\begin{array}{l}\text { Lamiaceae } \\
\text { (Labiatae) }\end{array}$ \\
\hline Feijão-bravo & Canavalia brasiliensis Mart. ex Benth. & Fabaceae \\
\hline $\begin{array}{l}\text { Vassourinha } \\
\text { Malva-branca } \\
\text { Guanxuma-branca } \\
\text { Guanxuma } \\
\text { - } \\
\text { Malva-roxa }\end{array}$ & $\begin{array}{l}\text { Sida carpinifolia } \mathrm{L} . \\
\text { Sida cordifolia } \mathrm{L} . \\
\text { Sida glaziovii } \mathrm{K} \text {. Schum. } \\
\text { Sida santaremnensis H. Monteiro } \\
\text { Sida } \text { sp. } \\
\text { Urena lobata } \mathrm{L} .\end{array}$ & Malvaceae \\
\hline $\begin{array}{l}\text { Cruz-de-malta } \\
\text { Cruz-de-malta }\end{array}$ & $\begin{array}{l}\text { Ludwigia leptocarpa (Nutt.) Hara } \\
\text { Ludwigia sericea (Camb.) Hara }\end{array}$ & Onagraceae \\
\hline Maracujá-de-estalo & Passiflora nigelliflora $\mathrm{L}$. & Passifloraceae \\
\hline Erva-gorda & Talium triangulare (Jacq.) Willd. & Portulacaceae \\
\hline $\begin{array}{l}\text { Mata-pasto } \\
\text { Vassourinha-de-botão }\end{array}$ & $\begin{array}{l}\text { Dioidia teres Walt } \\
\text { Spermacoce verticillata } \mathrm{L} .\end{array}$ & Rubiaceae \\
\hline Vassourinha & Scoparia dulcis L. & Scrophulariaceae \\
\hline Jurubeba, jubeba & Solanum paniculatum $\mathrm{L}$. & Solanaceae \\
\hline Chanana & Turnera ulmifolia $\mathrm{L}$. & Turneraceae \\
\hline $\begin{array}{l}\text { Cambará-de-espinho } \\
\text { Gervão }\end{array}$ & $\begin{array}{l}\text { Lantana camara L. } \\
\text { Stachytarpheta cayennensis (Rich.) Vahl }\end{array}$ & Verbenaceae \\
\hline
\end{tabular}


Tabela 2 - Freqüência (F) em porcentagem e densidade (D) em plantas $\mathrm{m}^{2}$ relativas das espécies de plantas daninhas encontradas, em função da cultura de cobertura

\begin{tabular}{|c|c|c|c|c|c|c|c|c|c|c|}
\hline \multirow{3}{*}{ Espécie } & \multicolumn{10}{|c|}{ Tratamento } \\
\hline & \multicolumn{2}{|c|}{ Mucuna } & \multicolumn{2}{|c|}{ Guandu } & \multicolumn{2}{|c|}{ Feijão-de-porco } & \multicolumn{2}{|c|}{ Calopogônio } & \multicolumn{2}{|c|}{ Controle } \\
\hline & $\mathrm{F}$ & $\mathrm{D}$ & $\mathrm{F}$ & $D$ & $\mathrm{~F}$ & $\mathrm{D}$ & $\mathrm{F}$ & $\mathrm{D}$ & $\mathrm{F}$ & $\mathrm{D}$ \\
\hline L. virgata & 24,0 & 23,8 & 31,8 & 35,8 & 38,9 & 16,6 & 27,6 & 39,0 & 20,7 & 26,4 \\
\hline P. laxum & 18,4 & 15,2 & 20,5 & 7,4 & 16,7 & 11,4 & 21,1 & 14,4 & 20,7 & 24,0 \\
\hline Sida sp. & 12,9 & 5,8 & 2,3 & 0,8 & 16,7 & 12,2 & 3,3 & 1,0 & 10,3 & 9,0 \\
\hline E. indica & 3,7 & 7,2 & - & - & 5,6 & 1,0 & 4,9 & 1,6 & 8,6 & 6,2 \\
\hline S. glaziovii & 11,1 & 2,2 & 2,3 & 0,8 & 2,3 & 0,2 & 4,9 & 1,4 & 6,9 & 0,8 \\
\hline P. conspersum & 3,7 & 0,8 & - & - & 2,3 & 0,4 & 4,9 & 1,8 & 3,4 & 1,6 \\
\hline S. carpinifolia & - & - & - & - & 5,6 & 2,2 & - & - & - & - \\
\hline T. geniculata & - & - & 2,3 & 1,8 & - & - & - & - & 3,4 & 0,4 \\
\hline C. bengalensis & - & - & 2,3 & 0,6 & - & - & 11,4 & 1,4 & - & - \\
\hline S. verticillata & 1,8 & 0,4 & 4,5 & 0,4 & - & - & - & - & 3,4 & 1,0 \\
\hline H. suaveolens & 5,5 & 0,6 & 2,3 & 0,2 & - & - & - & - & 5,2 & 0,8 \\
\hline P. nigelliflora & 3,7 & 0,4 & 4,5 & 0,4 & - & - & 1,6 & 0,2 & - & - \\
\hline T. triangulare & - & - & 2,3 & 0,4 & - & - & - & - & 1,7 & 0,4 \\
\hline Cyperus sp. & 3,7 & 0,8 & - & - & - & - & - & - & - & - \\
\hline S. santaremnensis & - & - & - & - & - & - & - & - & 3,4 & 0,8 \\
\hline S. indicus & - & - & - & - & - & - & 1,6 & 0,8 & - & - \\
\hline C. dactylon & - & - & - & - & - & - & 1,6 & 0,2 & 1,7 & 0,4 \\
\hline C. glandulosus & 1,8 & 0,2 & 2,3 & 0,2 & 2,3 & 0,2 & - & - & - & - \\
\hline L. martinicensis & - & - & - & - & - & - & - & - & 1,7 & 0,6 \\
\hline A. deflexus & 1,8 & 0,4 & - & - & - & - & - & - & - & - \\
\hline Chloris sp. & 1,8 & 0,4 & - & - & - & - & - & - & - & - \\
\hline C. flavus & - & - & 2,3 & 0,2 & - & - & 1,6 & 0,2 & - & - \\
\hline C. surinamensis & - & - & - & - & - & - & - & - & 1,7 & 0,4 \\
\hline E. comosa & 1,8 & 0,2 & 4,5 & 2,0 & - & - & - & - & - & - \\
\hline T. ulmifolia & - & - & - & - & - & - & - & - & 1,7 & 0,4 \\
\hline S. cordifolia. & 1,8 & 0,4 & - & - & - & - & - & - & - & - \\
\hline A. compressus & - & - & 2,3 & 0,2 & - & - & - & - & - & - \\
\hline C. esculentus & - & - & - & - & - & - & 3,3 & 0,2 & - & - \\
\hline Orbygnia spp. & - & - & 2,3 & 0,2 & - & - & - & - & - & - \\
\hline C. brasiliensis & - & - & - & - & 2,8 & 0,2 & - & - & - & - \\
\hline C. prostrata & - & - & - & - & - & - & 1,6 & 0,2 & - & - \\
\hline D. teres & - & - & - & - & - & - & 1,6 & 0,2 & - & - \\
\hline E. Alba & - & - & - & - & - & - & - & - & 1,7 & 0,2 \\
\hline E. sonchifolia & - & - & - & - & - & - & - & - & 1,7 & 0,2 \\
\hline L. camara & - & - & 2,3 & 0,2 & - & - & - & - & - & - \\
\hline L. leptocarpa & - & - & - & - & - & - & 1,6 & 0,2 & - & - \\
\hline L. sericea & - & - & - & - & 2,8 & 0,2 & - & - & - & - \\
\hline M. mudiflora & - & - & 2,3 & 0,2 & - & - & - & - & - & - \\
\hline S. dulcis & - & - & - & - & - & - & 1,6 & 0,2 & - & - \\
\hline S. paniculatum & 2,3 & 0,2 & - & - & - & - & - & - & - & - \\
\hline S. cayennensis & - & - & - & - & - & - & 1,6 & 0,2 & - & - \\
\hline U. lobata & - & - & - & - & 2,8 & 0,2 & - & - & - & - \\
\hline
\end{tabular}




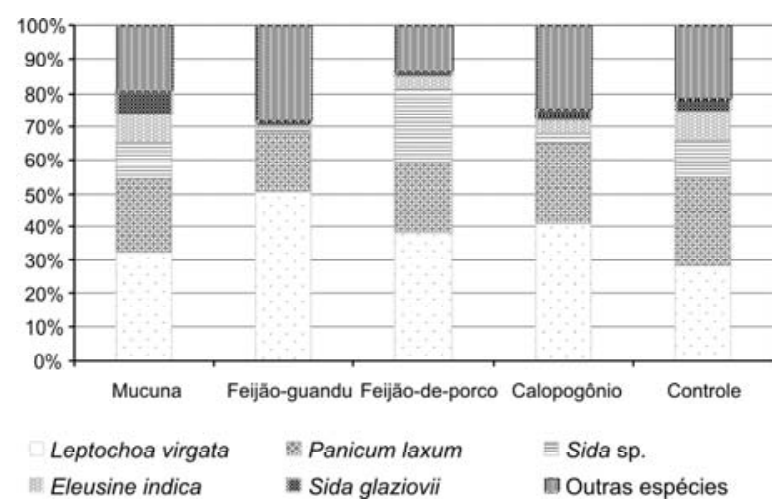

Figura 2 - Dominância relativa (\%) das principais espécies de plantas daninhas em função da espécie da cultura de cobertura.

condições favoráveis (chuvas). Nesse sentido, as chuvas extemporâneas ocorridas a partir da segunda quinzena de novembro e início de dezembro de 2003, antes do início da coleta dos dados, permitiram a recuperação da cobertura florística de plantas daninhas, quando a área do solo coberta pelas leguminosas era menor, em decorrência do estresse sofrido durante o período de estiagem. Essa recuperação das plantas daninhas nesse período provavelmente contribuiu para diminuir as diferenças entre os tratamentos, resultando, inevitavelmente, em resultados menos significativos $(\mathrm{P}>0,05)$ (Tabela 3).

A influência da produção de biomassa das leguminosas anuais sobre a densidade de plantas provavelmente está associada à capacidade das leguminosas em cobrir o solo. Segundo Favero et al. (2001), a mucuna-preta apresenta capacidade potencial alta na produção de biomassa, com produção de $6.987 \mathrm{~kg} \mathrm{ha}^{-1}$ de matéria seca na densidade de 100.000 plantas ha ${ }^{-1}$ e capacidade de cobrir $100 \%$ de solo em semanas após a emergência, em condições edafoclimáticas da região de Sete Lagoas - MG. Contudo, devido à sua baixa capacidade de tolerância à seca, como foi constatado neste experimento, e por apresentar hábito de crescimento com ramas que tendem a cobrir o componente arbóreo do sistema de cultivo em aléias - no caso deste experimento, o sombreiro -, a mucuna-preta não cobre o solo no período seco. O feijão-guandu, segundo Severino \& Christoffoleti (2004), quando usado como cultura de cobertura, foi eficiente na supressão de Brachiaria decumbens, Panicum maximum e Bidens pilosa, reduzindo a densidade dessas plantas semeadas propositadamente no experimento.

Neste estudo, não houve diferença significativa entre os tratamentos em relação ao número de espécies de plantas daninhas, embora o menor número delas tenha sido encontrado no tratamento em que a cultura de cobertura foi o feijão-de-porco (Tabela 3), provavelmente devido ao seu efeito na redução do banco de sementes. Quanto à análise do índice de diversidade de espécies de Shannon-Wiener (H), que atribui peso maior às espécies raras e varia de 0 a 1,0 (Odum, 1988), os tratamentos controle e mucuna-preta apresentaram o maior indice $(\mathrm{H}=1,0)$ e o feijão-de-porco, o menor $(\mathrm{H}=0,8)$ (Tabela 3), sugerindo que esta leguminosa pode ter contribuído para a exclusão de algumas espécies. A similaridade da composição florística entre os tratamentos foi considerada baixa, tendo variado de $32,3 \%$ a $51,8 \%$ (Tabela 3). Apenas os tratamentos com mucuna-preta e feijão-de-porco mostraram similaridade superior a $50 \%$; a menor

Tabela 3 - Efeitos das espécies usadas como cultura de cobertura sobre densidade, número de espécies, índice de diversidade de Shannon-Wiener e biomassa das plantas daninhas (média \pm erro-padrão da média)

\begin{tabular}{|c|c|c|c|c|}
\hline Tratamento & Densidade & $\mathrm{N}^{\mathrm{o}}$ de espécies & Diversidade & Biomassa \\
\hline & plantas $\mathrm{m}^{2}$ & ${\text { espécies } \mathrm{m}^{-2}}^{-2}$ & (índice de Shannon-Wiener) $^{-2}$ & $\mathrm{~g} \mathrm{~m}^{-2}$ \\
\hline Mucuna & $59,0( \pm 12,2)$ & $5,2( \pm 1,1)$ & $1,0( \pm 0,2)$ & $377,9( \pm 93,8)$ \\
\hline Guandu & $51,8( \pm 11,3)$ & $5,2( \pm 1,7)$ & $0,9( \pm 0,4)$ & $392,9( \pm 58,4)$ \\
\hline Feijão-de-porco & $44,8( \pm 6,1)$ & $3,8( \pm 0,8)$ & $0,8( \pm 0,2)$ & $158,6( \pm 49,8)$ \\
Calopogônio & $53,4( \pm 9,5)$ & $6,4( \pm 1,6)$ & $1,0( \pm 0,2)$ & $414,6( \pm 24,4)$ \\
Controle & $73,8( \pm 16,5)$ & $6,4( \pm 1,1)$ & $1,0( \pm 0,2)$ & $428,4( \pm 122,8)$ \\
\hline
\end{tabular}


similaridade, de 32,3\%, ocorreu entre os tratamentos feijão-de-porco e calopogônio. A similaridade entre os tratamentos está fundamentada, basicamente, nas quatro espécies dominantes.

Não houve diferença significativa $(\mathrm{P}>0,05)$ na produção de biomassa das plantas daninhas em relação às quatro leguminosas de cobertura, nem destas em relação ao controle (Tabela 3). Mesmo entre os tratamentos com feijão-deporco e controle, em que a produção média de biomassa das plantas daninhas foi de 158,6 e $428,0 \mathrm{~g} \mathrm{~m}^{-2}$, respectivamente, não houve diferença significativa, provavelmente devido a grande variação ocorrência nas parcelas de cada um destes tratamentos. Da mesma forma, a análise da regressão linear entre a biomassa das leguminosas e a biomassa das plantas mostrou baixa relação de dependência entre essas variáveis.

Fávero et al. (2001) observaram que a maior eficiência de leguminosas em diminuir a biomassa de plantas daninhas está relacionada à sua capacidade de produção de biomassa, ou seja, quanto maior for a capacidade de a leguminosa produzir biomassa e cobrir o solo, maior será a eficiência na diminuição da biomassa. $\mathrm{Na}$ comunidade científica e, por extensão, entre a maioria dos agricultores existe o consenso de que culturas de cobertura são capazes de reduzir a infestação de plantas daninhas em agroecossistemas. Contudo, a dinâmica de distribuição das espécies de plantas em um local também é fortemente influenciada pelo banco de sementes existente e por fatores edafoclimáticos (N'zala et al., 2002). Por isso, o efeito das culturas de cobertura sobre a incidência de plantas daninhas pode variar muito. Hatcher $\&$ Melander (2003) relatam casos em que o centeio usado como cultura de cobertura não influenciou a densidade, a composição e a biomassa das espécies de plantas daninhas em sistemas de plantio direto de soja e milho, durante nove anos de estudo. Estes autores comentam também casos em que as culturas de cobertura conseguem controlar apenas algumas espécies, enquanto outras acabam por dominar a área. Ikuenobe \& Anoliefo (2003), avaliando a influência de Mucuna pruriens e Chromolaena odorata, utilizadas como culturas de pousio, sobre a infestação de plantas daninhas, verificaram que, mesmo havendo diferença na biomassa das plantas entre essas leguminosas, nos dois primeiros anos de implantação do sistema, a biomassa das plantas daninhas foi praticamente a mesma, ocorrendo reduções significativas só a partir do terceiro ano.

Como principal conclusão deste trabalho, pode ser relatado que as culturas de cobertura exercem efeitos supressivos distintos sobre as diferentes espécies da população de plantas do agrossistema. Por isso, para um sistema agroecológico e nas condições deste experimento, mais racional seria o uso continuado com rotação anual das leguminosas, e o feijão-de-porco e o feijão-guandu seriam as mais recomendadas, em razão de sua maior tolerância à seca e capacidade supressiva.

\section{LITERATURA CITADA}

BOND, W.; GRUNDY, A. C. Non-chemical weed management in organic farming systems. Weed Res., v. 41, p. 283-405, 2001

FAVERO, C. et al. M. Modificações na população de plantas espontâneas na presença de adubos verdes. Pesq. Agropec. Bras., v. 36, n. 11, p. 1355-1362, 2001.

FERRAZ JUNIOR, A. S. L. Arroz de sequeiro em sistema de cultivo em aléias sobre solo de baixa fertilidade natural. 2000. 186 f. Tese (Doutorado em Agronomia/Solos e Nutrição de Plantas) - Universidade Federal Rural do Rio de Janeiro, Seropédica, 2000.

GLIESSMAN, S. R. Agroecologia: processos ecológicos em agricultura sustentável. 2. ed. Porto Alegre: Universidade Federal do Rio Grande do Sul, 2001. 653 p.

HATCHER, P. E.; MELANDER, B. Combining physical, cultural and biological methods prospects for integrated nonchemical weed management strategies. Weed Res., v. 43, p. 303-322, 2003.

HYVÖNEN, T.; KETOJA, E.; SALONEN, J. Changes in the abundance of weeds in spring cereal fields in Finland. Weed Res., v. 43, p. 348-356, 2003.

IKUENOBE, C. E.; ANOLIEFO, G. O. Influence of Chromolaena odorata and Mucuna pruriens fallow duration on weed infestation. Weed Res., v. 43, p. 199-207, 2003.

JAKELAITIS, A. et al. Dinâmica populacional de plantas daninhas sob diferentes sistemas de manejo nas culturas de milho e feijão. Planta Daninha, v. 21, n. 1, p. 71-79, 2003.

KISSMANN, K. G.; GROTH, D. Plantas infestantes e nocivas. São Paulo: Basf, 1992. Tomo II. 798 p. 
KISSMANN, K. G.; GROTH, D. Plantas infestantes e nocivas. São Paulo: Basf, 1995. Tomo III. 683 p.

KISSMANN, K. G. Plantas infestantes e nocivas. 2. ed. São Paulo: Basf, 1997. Tomo I. 824 p.

MARENCO, R. A.; SANTOS, A. M. B. Crop rotation reduces weed competition and increases chlorophyll concentration and yield of rice. Pesq. Agropec. Bras., v. 34, n. 10, p. 1881-1887, 1999.

MARSHALL, E. J. P. et al. The role of weeds in supporting biological diversity within crop fields. Weed Res., v. 43, p. 77-89, 2003.

MOURA, E. G. Agroambientes de transição avaliados numa perspectiva da agricultura familiar. In: MOURA, E. G. (Org.) Agroambientes de transição entre o trópico úmido e o semi-árido do Brasil: atributos; alternativas; uso na produção familiar. São Luís: Universidade Estadual do Maranhão, 2004. p. 15-51.

N'ZALA, D.; NADJIDJIM, J.; NGAKA, A. Weed population dynamics during the groundnut crop cycle in the wet tropical zone of Kombe (Congo). Weed Res., v. 42, p. 100-106, 2002.
ODUM, E. P. Ecologia. Rio de Janeiro: Guanabara, 1988. $434 \mathrm{p}$.

PINTO-COELHO, R. M. Fundamentos em ecologia. Porto Alegre: Artmed, 2000. 252 p.

POUDEL, D. D. et al. Comparison of soil $\mathrm{N}$ availability and leaching potential, crop yields and weeds in organic, lowinput and conventional farming systems in northern California. Agric. Ecosys Environ., v. 90, p. 125-137, 2002.

SENARATHNE, S. H. A.; SAMARAJEEWA, A. D.; PERERA, K. C. P. Comparison of different weed management systems and their effects on yield of coconut plantations in Sri Lanka. Weed Biol. Manag., v. 3, p. 158161, 2003.

SEVERINO, F. J.; CHRISTOFFOLETI, P. J. Weed supression by smother crops and selective herbicides. Sci. Agric., v. 61, n. 1, p. 21-26, 2004.

WILLIAMS II, M. M.; MORTENSEN, D. A.; DORAN, J. W. Assessment of weed and crop fitness in cover crop residues for integrated weed management. Weed Sci., v. 46, p. 595-603, 1998. 